\title{
SERVIÇO SOCIAL E EDUCAÇÃO PERMANENTE EM SAÚDE: A POTENCIALIDADE PARA INTEGRAÇÃO ENSINO-SERVIÇO
}

\author{
SOCIAL WORK AND PERMANENT HEALTH EDUCATION: THE POTENTIAL FOR \\ INTEGRATION SERVICE-LEARNING \\ TRABAJO SOCIAL Y EDUCACIÓN PERMANENTE EN SALUD: EL POTENCIAL DE \\ APRENDIZAJE-SERVICIO
}

Recebido: 10/03/2015

Aprovado: 05/12/2015
Fernanda de Oliveira Sarreta ${ }^{1}$

Fumie Eto ${ }^{2}$

Daiane Cristina dos Santos Brentini ${ }^{3}$

Danielle de Oliveira Nogueira ${ }^{4}$

Gabriela Cristina Braga Bisco 5

Este artigo tem como objetivo propiciar reflexão acerca da educação permanente em saúde (EPS), estratégia adotada no Sistema Único de Saúde para a formação e o trabalho em saúde. A partir da contribuição do método dialético, o estudo bibliográfico, a coleta de dados em grupo focal e a observação em campo, busca-se compreender o enfrentamento dos limites e as alternativas dos sujeitos no cenário contemporâneo - estudantes de serviço social e trabalhadores de saúde. Os resultados revelam que a EPS é de difícil exercício, já que busca a ruptura com práticas verticalizadas e o compromisso ético e político com a saúde pública e, coloca em foco, os valores e concepções sobre o contexto onde se gestam as políticas públicas, o sistema capitalista. Considera-se que a estratégia potencializa a integração ensino-serviço e a busca de respostas coletivas aos problemas.

Descritores: Serviço Social; Política de saúde; Educação permanente.

This article aim the provide reflection about of permanent health education, strategy adopted in the health system of Brazil (SUS) for formation and health work. From the dialectical method contribution, the bibliographic study, the data collection in focus groups and observation in the field, try to understand the limits of coping and alternatives of the subjects in the contemporary scene - students of social work and health workers. The results show that the EPS is difficult to exercise, since it search the break with vertically integrated practices and the ethical and political commitment to public health, putting on reflection values and conceptions about the context where they bear public policy, the capitalist system. It is considered that the strategy enhances the teaching-service integration and the search for collective responses to problems.

Descriptors: Social Work; Health policy; Permanent health.

Este artículo tiene como objetivo proporcionar reflexión a cerca de la educación permanente, estrategia de salud adoptada por el sistema de salud brasileño (SUS) para la formación y el trabajo en salud. A partir de la contribución del método dialéctico, el estudio bibliográfico, la recopilación de datos en el grupo focal y la observación de campo, se procura entender los límites de afrontamiento y como alternativas a los sujetos en la escena contemporánea - estudiantes de servicio social y trabajadores de la salud. Los resultados muestran que la EPS és un ejercicio difícil, ya que la busqueda por la rotura con prácticas verticalizadas y el compromiso ético y político con la salud pública, coloca en foco los valores y concepciones sobre el contexto donde se generan las políticas públicas, el sistema capitalista. Si considera que la estrategia potencializa la integración enseñanza-servicio y la busqueda de respuestas colectivas a los problemas.

Descriptores: Servicio Social; Política de salud; Educación Permanente.

\footnotetext{
${ }^{1}$ Assistente Social. Mestre e Doutora em Serviço Social. Professora Assistente da Graduação e do Programa Pós-Graduação da Faculdade de Ciências Humanas e Sociais - UNESP, Campus de Franca/SP e líder do Grupo de Estudos e Pesquisas sobre Saúde, Qualidade de Vida e Relações de Trabalho - QUAVISSS. ferssarreta2009@yahoo.com.br

${ }^{2}$ Assistente Social. Bacharel em Direito. Mestre e Doutora em Serviço Social. Professora do Curso de Serviço Social e Direito do Centro Universitário da Fundação Educacional de Guaxupé - UNIFEG/MG. Assistente Social Supervisora Técnica da Seção Técnica de Saúde da Faculdade de Ciências Humanas e Sociais da UNESP, Campus de Franca/SP. Membro e Pesquisadora do QUAVISSS.

${ }^{3}$ Graduanda em Serviço Social e Bolsista de Monitoria/UNESP. Membro e Pesquisadora do QUAVISSS.

${ }^{4}$ Assistente Social. Mestranda em Serviço Social. Assistente Social da Santa Casa de Franca/SP. Membro e Pesquisadora do QUAVISSS.

${ }^{5}$ Graduanda em Serviço Social e Bolsista PIBIC/CNPq. Membro e Pesquisadora do QUAVISSS.
} 


\section{INTRODUÇÃO}

0 interesse pelo tema da Educação Permanente em Saúde (EPS) resulta de uma trajetória de experiências, debates, estudos e pesquisas, desde a sua regulamentação como política pública para a formação e desenvolvimento dos trabalhadores de saúde. E, das inquietações relacionadas à efetivação do Sistema Único de Saúde (SUS), por meio de estágios, da extensão, do trabalho cotidiano nas unidades de saúde, que motivam a busca de respostas para o enfrentamento das diferentes manifestações das desigualdades sociais, numa perspectiva histórica que apreenda o movimento contraditório da política pública de saúde. Portanto, esta é a intencionalidade deste estudo, reconhecendo que só se investiga aquilo que se conhece e inquieta, reflete Minayo1: "ou seja, nada pode ser intelectualmente um problema, se não tiver sido, em primeiro lugar, um problema da vida prática".

No âmbito do Serviço Social, o debate sobre a Política de Educação Permanente em Saúde (EPS) está cada vez mais fortalecido na categoria profissional, que reconhece esta estratégia como resultante de um movimento histórico que reafirma a responsabilidade do Estado em ordenar a formação de recursos humanos para a saúde ${ }^{2}$. A profissão reconhece, sobretudo, que é uma política transversal e abrange todas as instâncias e ações do SUS, colocando o desafio de pensar os processos formativos a partir das realidades loco-regionais e dos problemas que impedem a atenção integral em saúde.

As proposições do Projeto Ético-Político do Serviço Social estão articuladas ao Projeto da Reforma Sanitária brasileira, visando efetivar a universalização do acesso à saúde com qualidade. São projetos que enunciam princípios e diretrizes para a construção de relações democráticas, na perspectiva do desenvolvimento da autonomia e emancipação dos sujeitos e de ruptura com práticas autoritárias, centralizadoras e assistencialistas. Deste modo, antagônicos ao projeto defensor do neoliberalismo, que promove a redução dos direitos sociais, sucateamento dos serviços públicos, enxugamento do papel do Estado e redução das políticas sociais ${ }^{3}$.

A atuação do assistente social na saúde fundamentada no Projeto Ético-Político deve estar articulada ao Projeto da Reforma Sanitária ${ }^{4}$. Portanto, é na referência destes projetos que a profissão pode fornecer subsídios para o fortalecimento do usuário e sua participação na saúde, ampliando as possibilidades de influência nas decisões que interessam a estes sujeitos.

Do mesmo modo, as atribuições do assistente social na saúde, refletidas nos Parâmetros para Atuação na Saúde ${ }^{5}$, qualificam o profissional para atuar com competência nas diferentes dimensões da questão social no âmbito da política de saúde. Este instrumento direciona o exercício profissional para a construção de respostas que ampliem o atendimento das necessidades sociais e reafirma 0 posicionamento em favor da equidade e justiça social na saúde. Assim, ao valorizar a atividade científica por meio da pesquisa, o assistente social gera dados ligados às condições de vida da população, à reprodução das relações sociais, à implementação das políticas sociais. As informações de experiências desenvolvidas e socializadas podem contribuir na elaboração de propostas mais apropriadas às necessidades sociais e de saúde.

A dimensão investigativa ${ }^{6}$ está estabelecida no projeto profissional como condição central da formação e da relação teoria e realidade, afirmando-se como parte constitutiva do exercício profissional. Esta dimensão é fundamental para o enfrentamento dos desafios contemporâneos, a qual deve partir de situações concretas da realidade, abrangendo os condicionantes históricos, sociais, econômicos, culturais, e as contradições e conflitos do cotidiano da saúde, para desvendar o que é imediato e ir além do que está aparente? ${ }^{7}$.

É neste direcionamento que se situa este estudo, comprometido com a busca de respostas aos problemas colocados para a efetivação da universalidade, integralidade e equidade da atenção à saúde. 
Assim, este estudo tem como objetivo propiciar reflexão acerca da educação permanente em saúde (EPS), estratégia adotada no Sistema Único de Saúde para a formação e o trabalho em saúde.

\section{MÉTODO}

Esta é uma pesquisa qualitativa. A opção por este tipo de pesquisa assinala a possibilidade de desvendar este contexto que reproduz injustiças, desvaloriza o que é público e julga como bom o que é oferecido pelo mercado, para a construção do conhecimento que ajude no enfrentamento desses desafios.

A pesquisa qualitativa ajuda a recuperar a questão da sociabilidade humana, possibilitando pensar o município e região como espaço de construção, de pertencimento e de referência dos sujeitos ${ }^{8}$. A construção de práticas coletivas passa, fundamentalmente, pela questão da pesquisa, ou seja, discutir a formação dos trabalhadores de saúde exige a análise do contexto onde ela se realiza.

Com essa proposição investigativa o Grupo de Estudos e Pesquisas sobre Saúde, Qualidade de Vida e Relações de Trabalho (QUAVISSS) da UNESP Franca/SP, responsável pela pesquisa, caracterizou-se como espaço de referência no debate da política nacional de saúde e o desenvolvimento do SUS e a sua conformação local, regional e nacional. O Grupo está comprometido com a produção de conhecimentos sobre a atuação do assistente social na saúde e a formulação de respostas e alternativas para atuar nas diferentes dimensões da questão social. Busca contribuir no debate teórico e político orientado pelo Projeto da Reforma Sanitária e Projeto Ético-Político do Serviço Social, aproximando o entendimento de saúde como direito humano a perspectiva de totalidade social ${ }^{9}$.

Esta investigação foi aprovada pelo Conselho de Ética em Pesquisa da Faculdade de Ciências Humanas e Sociais de Franca UNESP, sob o protocolo 623.182/2014, e contou com apoio do Conselho Nacional de Desenvolvimento Científico e Tecnológico (CNPq), Processo 406432/2012-0.
O estudo foi desenvolvido de 2013 a 2014, no cenário da rede de saúde do município de Franca/SP e sua região de abrangência com 22 municípios, mediante pesquisa bibliográfica e coleta de dados a partir da combinação de técnicas, ou seja, a triangulação de dados com a utilização do grupo focal e da observação participativa em campo, os quais permitem o aprofundamento do tema ${ }^{10}$.

A escolha dos sujeitos da pesquisa alunos de serviço social da graduação ou pósgraduação e trabalhadores de saúde consideraram os objetivos, os pressupostos teóricos e o movimento da realidade. A escolha dos sujeitos teve como critérios: participação no Grupo QUAVISSS há mais de um (1) ano, frequência de $50 \%$ nas atividades e estar inserido em unidades de saúde como: alunos de serviço social (estagiários e pesquisadores da pósgraduação) e trabalhadores de saúde (assistente sociais, psicólogos e gestores de serviços).

Nas pesquisas qualitativas em ciências sociais a técnica de coleta de dados no grupo focal vem sendo reconhecida para a problematização de um tema específico ${ }^{11}$. E desenvolve-se a partir de uma perspectiva dialética, onde o grupo possui objetivos comuns e seus participantes procuram abordá-los trabalhando como uma equipe, o que coincide com a opção da escolha do Grupo QUAVISS como espaço privilegiado da pesquisa, para o alcance de concepções coletivas sobre a formação e o trabalho em saúde e a integração ensino-serviço.

A composição do grupo focal seguiu as orientações para a utilização desta técnica ${ }^{12}$, e os encontros revelaram-se prazerosos e satisfatórios. 0 debate foi estimulado a partir dos seguintes tópicos: Qual o conhecimento ou opinião sobre o SUS? 0 que significa saúde como direito universal e integral? O Grupo QUAVISSS desenvolve espaços de aprendizagem? Como potencializar a integração ensino-pesquisa-serviço? A identidade e anonimato dos sujeitos está preservada, os quais são identificados como: sujeito (S) - aluno (A) ou trabalhador (T), e a numeração correspondente; para o destaque 
das falas, optou-se pelo itálico. Respeitandose o desafio de construir um diálogo na pesquisa, decidiram-se apresentar no corpo do texto as falas de alguns sujeitos, seus sentimentos e entendimentos sobre a saúde. Buscou-se demonstrar a construção como parecer coletivo, enriquecendo as reflexões e os resultados esperados.

\section{RESULTADOS}

Ao refletir sobre os espaços de aprendizagem criados pelo Grupo QUAVISSS, como Rodas de Conversas, Oficinas Temáticas, entre outros, as falas revelam a importância destes espaços coletivos:

Acho assim, que um membro do Grupo que trabalha na área da saúde, tendo essa visão mais ampla, talvez leve pro ambiente de trabalho e consegue essa mudança, né? Por que seria super interessante conseguir essa integração, apesar de que é muito difícil, [...] mas começar já a demonstrar isso, já é um passo muito grande. (SA4)

Vejo assim, numa das coisas que o Grupo QUAVISSS consegue é concreto. Tem essa coisa que é da nossa formação, eu como assistente social [...], eu sempre tô em permanente formação, porque se eu ficar só na rotina do trabalho, eu vejo que isso realmente distância. Eu vejo que tem que procurar esses espaços, $e$ a universidade ela deve criar. Eu acho que o QUAVISSS favorece isso, é um espaço de formação para o SUS. (ST1)

Eu particularmente, eu faço a opção de vir no QUAVISSS, porque essa questão da construção, fica melhor eu escutar de alguém do que eu só ficar lendo. $E$ esse negócio de roda, assim, a pessoa tá dando atenção pra o que você tá falando [...], pra mim vale mais do que estudar e pensar sozinha. (SA4)

E o vínculo que cria, a entrada de outros profissionais no Grupo, é muito bom mesmo [...]. Através dos alunos mesmo, que trazem as questões do estágio, o que houve de mudança, as políticas, e acaba tendo conhecimento e acesso a essas políticas públicas, não se afasta das políticas. E outra coisa [...] é que as vezes eu encontro alunos que fizeram parte do Grupo e estão trabalhando na saúde. Então, o Grupo contribui no fortalecimento desse profissional, ele tem um posicionamento de defesa do SUS [...]. E estão super bem, e trabalhando dentro dessa formação de defesa de efetivação também. E eles estão sempre em formação. Porque a questão do trabalho ele precariza sim, distância, a própria condição do trabalho distância. (ST1)

Observa-se nas falas as transformações da realidade e relações sociais:

Na minha visão o SUS foi muito importante para a sociedade. Porque antes ele não era direito universal, com todos os serviços integrados, era um serviço destinado só para aquelas pessoas que contribuíam. Com o SUS, esse direito passou a ser um direito universal, apesar de que ele é um direito garantido, mas muitas vezes a gente vê a dificuldade dele se efetivar mesmo. De ser um serviço de qualidade e que atenda toda a população. (SA1)

E não é que é direito universal, que é pra todos. E ainda, o SUS tem isso mesmo, pra aqueles que é mais rico, mais pobres, [...] como um serviço diferente. O SUS visto como que um serviço que o público é muito ruim, e o privado muito bom. (SA2)

Eu que vi, que vivi, esse processo de implantação do SUS, a diferença que houve, é a questão do acesso realmente, de ser universal. [...] O SUS é uma política universal de acesso igualitário. Então, a gente percebe que houve uma mudança, e muito boa. Agora, na questão da efetivação, é lógico, a gente vê que é bem claro a questão da contramão pra que esse SUS não dê certo. Eu vejo muito claro [...] que o governo tem que assumir mesmo. Educação e saúde é uma responsabilidade pública. Porque se isso cair no mercado a qualidade realmente fica questionável. Porque aí o que vai valer é a questão do ganho, e não a qualidade. (ST1)

A indicação de movimento contra hegemônico, seguido de resistências para a construção do SUS é verificada nas falas:

E eu não sei se o problema é a falta de efetivação dele, do SUS, e dele ser um jovem ainda. Porque foi um processo histórico de muita luta, pra conseguir que ele fosse implementado, e antes era só os contribuintes. Então, uma grande parcela da população era excluída do Sistema. E foi só em 1988 que ele foi constituído mesmo como Sistema universal. E é bem assim, prá uma história, é recente. E o que dá medo é se ele vai continuar [...], esses obstáculos, pra que o SUS seja efetivado. E que os próximos 30 anos, será que ele vai atingir a terceira idade? Ele vai conseguir ser efetivado? Ser pleno, garantir plenamente todos os direitos, de todos os cidadãos? (SA3)

Agora, quando se fala das diretrizes, que tem a política de saúde, [...] tem poucas pessoas que tem esse conhecimento. E isso é que é o desafio, na área da educação, o que precisa pra efetivar o SUS? [...] É educação, é formação. E que formação é essa? O que o Estado está garantindo pras universidades, pra formar trabalhadores pro SUS? (ST1)

Eu não conheço bem a fundo. Eu penso no SUS como um desafio. Um eterno desafio [...]. Eu vejo o SUS como um desafio, de conseguir efetivar aquilo que ele preza. [...] $E$, a palavra que define pra mim é desafio. O desafio de conseguir a efetivação. (SA4)

É a carga de trabalho e o acúmulo das atividades, e a falta de integração entre as equipes. (ST1)

A sobrecarga de trabalho, o acumulo de funções, a falta de comprometimento da equipe, falta de motivação, não tem valorização, tudo isso. [...] E tem as influências do político, $e$ a desvalorização dos funcionários $e$ a desmotivação. (ST2)

A carga de trabalho e o acúmulo de funções, é uma sobrecarga, fazendo com que não realizamos as funções como a gente deveria. (ST3)

A grande carga de trabalho e falta de funcionário é o maior problema. Tem muita cobrança e a questão

REFACS (online) 2016; 4(1):17-25. 
política partidária na saúde. A falta de recursos materiais, a desmotivação de funcionários as falhas no processo de comunicação e não tem trabalho em equipe, nem comprometimento. [...] E a falta de capacitação dos funcionários é um problema. (ST4)

A formação em serviço proposta pela EPS vai além das capacitações e treinamentos isolados e voltados para problemas imediatos dos serviços, visto na descrição a seguir:

Essa formação que estamos falando pode acontecer em qualquer espaço, é a proposta da educação permanente, ela está em todo lugar, não é? (ST3).

As possibilidades de transformar o cotidiano da saúde estão em pequenas atitudes e alternativas, as quais poderiam ser consideradas no processo de trabalho:

A capacitação para funcionários é importante [...]. Outra coisa é a contratação, e perguntar o que tem mais habilidade, a afinidade e ver a formação da pessoa [...]. (ST3)

Deixar claro os papéis, as funções de cada profissional, $e$ procurar identificar e ressaltar os pontos positivos. Acreditar que pode dar certo, e acreditar nas mudanças. Precisa incentivar, estimular os profissionais da equipe. Assim podemos melhorar no espaço do nosso trabalho. (ST2)

Temos conhecimento e vivência profissional, precisamos continuar fazendo cursos de educação permanente para fortalecer o trabalho [...]. (ST4)

Não pode esquecer da importância da leitura das políticas de saúde, é um compromisso [...], e elaborar projetos no município a partir dos problemas levantados (ST2)

A disposição para um novo aprendizado pode gerar inquietude, desconforto, insatisfação, desejo de busca e de um novo aprendizado em saúde, para que seja um espaço de encontro, partilha, respeito, tolerância e diálogo, como nas falas:

Eu fiz um curso de formação da educação permanente [...]. E é assim, aqui também, não estão tendo espaço de formação. Porque formação não é só fazer os cursos que o Ministério da Saúde oferece, formação também acontece no próprio espaço de trabalho. Por exemplo, [...] formação não é o que é fornecido pela faculdade, é o próprio espaço de trabalho, tem que criar uma discussão. E não é o que acontece, estes espaços não estão sendo facilitados. $E$ os trabalhadores, por outro lado, estão desorganizados, no sentido de não cobrar isso, de que no horário de trabalho ter esse espaço, ter reunião de equipe. Pra mim reunião de equipe é formação também. (ST1)

No local onde eu faço estágio é tudo separado. [...] Tinha que ter integração de toda a equipe, de ter participação de todo mundo. Não tá tendo integração dos trabalhadores. (SA1)

Acho que ela, a EPS, seria a porta de entrada, pra conscientização [...]. É uma coisa que o próprio profissional desconhece, ele faz, mas desconhece. O profissional desconhece, a política que ele tá inserido, a história, a valorização dos profissionais quanto ao SUS. (SA4)

Discutir o trabalho deveria fazer parte do trabalho. E a gente vê que não é assim. A discussão do trabalho, do trabalhador da saúde principalmente, não entra em pauta. O que é o SUS? Muita gente, os trabalhadores em geral, não tem noção do que é o SUS. Então, eles ficam tudo alienado, e não tem importância pras coisas que pode melhorar o atendimento. (ST2)

A necessidade de uma formação problematizadora é apontada pelos pesquisados:

E a importância do aluno ver, que esses profissionais, que já se formou, e está buscando esta formação profissional, o tanto que é importante. Porque a formação não acaba na universidade, é sempre permanente. (SA1)

O profissional se não buscar essa formação sempre, fica muito fechado na instituição, vai deixando o trabalho ruim, vai deixando desmotivado [...]. Então, esses espaços são importantes pra debater, inclusive a postura do profissional. (ST2)

É aqui no Grupo QUAVISSS vai numa construção gradativa. E mesmo se eu, como futuro profissional, se não me inserir na área da saúde, por exemplo ir trabalhar no CRAS, é extremamente necessário eu saber o que é o SUS, os encaminhamentos possíveis, pra eu orientar a população usuária. Tanto que, independente do concurso que você vai prestar pra assistente social, você tem que saber sobre a formação do SUS, a lei. Você tem que saber se for prestar concurso, você tem que saber a lei... a lei da Maria da Penha, a lei da criança e adolescente. É uma coisa integrada, é um assistente social com melhor competência, tem que tá aberto a qualquer formação. (SA3)

A perspectiva de um trabalho mais humano, agradável e valorizado é descrito pelos pesquisandos:

Precisa melhorar a estrutura física e ser mais agradável. Ter plano de carreira e atribuições bem definidas, a gente ter autonomia [...]. Precisa melhorar o ambiente e valorizar os funcionários. (ST3)

Com pequenas mudanças, começando por nos autovalorizar, por exemplo a humildade, a compreensão, o companheirismo, respeito e humanidade. Fazendo pro outro, aquilo que gostaria que fizessem com a gente, ser humano. Dessa forma estaremos aos poucos fazendo com que a humanização seja executada. (ST5)

Os sujeitos expressam a dimensão coletiva do trabalho em saúde, a partir de suas experiências:

Nós sugerimos que sejam convidados um articulador de educação permanente por unidade de saúde [...]. Enfim, queremos mais participantes das UBS e ESF no curso para garantir mudança no modelo e na atuação, conforme a política do SUS. (ST3)

Sabe, precisa da construção de um projeto baseado nos interesses e nas necessidades do coletivo [...], partindo

REFACS (online) 2016; 4(1):17-25. 
do princípio da transversalidade. E que a estratégia para coletar as temáticas seja através de pesquisa de interesse junto aos trabalhadores, garantindo a participação de todos [...]. (ST2)

\section{DISCUSSÃO}

As experiências construídas no Grupo QUAVISSS mostram que o conhecimento se constrói a partir do cotidiano, na possibilidade de colocar a teoria em movimento, seja pela mediação da pesquisa ou da extensão, seja pela mediação do estágio ou do trabalho. É nesta relação dialética da prática-teoria-prática que os sujeitos projetam seus anseios, desejos, inquietações e realizações, se realizam por inteiro e se humanizam.

A atividade de desvendamento e transformação da realidade considera as transformações que emergem na cena contemporânea e alteram significativamente as relações sociais, e produzem novas necessidades, exigindo profissionais comprometidos com o enfrentamento de suas manifestações. É com este olhar que a política pública de saúde deve ser refletida, analisada e defendida.

No cenário atual, de intensas transformações societárias ${ }^{3}$, a precarização do trabalho em saúde se dá em todos os níveis, não apenas no baixo salário, como na infraestrutura, na violação dos direitos dos trabalhadores, no empobrecimento da população que reflete no trabalhador, ou seja, é um cenário que está pedindo um olhar ético e político. É onde se situa a relação entre o trabalho cotidiano realizado na saúde e a temática desta pesquisa, o que remete ao pensamento de Minayo ${ }^{1}$ :

A saúde enquanto questão humana [...] é uma problemática compartilhada [...] por todos os seguimentos sociais. Porém as condições de vida e de trabalho qualificam de forma diferenciada a maneira pela qual as classes e seus segmentos pensam, sentem $e$ agem a respeito dela.

0 objeto das ciências sociais é histórico, o que esclarece a escolha do método sócio histórico que orienta este estudo, pois "não é apenas o investigador que dá sentido a seu trabalho intelectual, mas os seres humanos, os grupos e as sociedades dão significado e intencionalidade a suas ações objetivadas" 1 . Esta escolha imprime a visão social de mundo e o posicionamento ético-político do Grupo QUAVISSS, uma vez que as motivações deste estudo nasceram das inquietações e questionamentos da realidade vivida e sentida pelos sujeitos. Portanto, é preciso problematizar e questionar as estruturas que a determinam, pois a análise de aspectos isolados da realidade não é capaz de corresponder a sua concreticidade e revelar a sua essência7.

0 movimento de resistência à desconstrução da universalidade do SUS enquanto política pública organiza-se na defesa do Projeto da Reforma Sanitária brasileira. Pode-se afirmar que este movimento social contra hegemônico, resiste às indicações neoliberais que informa políticas públicas restritas, focalizadas e indica a privatização e terceirização como alternativas viáveis para a saúde da população.

Ao refletir a educação permanente como política pública, os sujeitos enfocam que o Sistema Único de Saúde (SUS) brasileiro é reconhecido como importante conquista da sociedade, no entanto, enfrenta grandes desafios para efetivar os princípios fundamentais que orientam sua efetivação, a universalidade, integralidade e equidade da atenção à saúde. Essa nova formulação organizacional, como política pública do Estado $^{13}$, reconhece a saúde em seu conceito abrangente, relacionada aos fatores condicionantes e determinantes das condições de vida e de trabalho. 0 diálogo entre os sujeitos expressa os avanços e as contradições que envolvem a efetivação do SUS.

A EPS exige o exercício do trabalho em equipe voltado ao processo educativo que valorize o conhecimento tido como "nãocientífico" e aquele reconhecido como científico. E, que seja estruturado sob o conceito ampliado de saúde, no qual as várias disciplinas alternam papéis na construção da atenção integral a saúde e sua promoção. É nesse sentido que as práticas de educação saem das agendas acadêmicas, para se integrarem às práticas dos serviços públicos.

No que se refere ao distanciamento da formação e prática, a EPS indica a criação dos 
espaços de ensino-aprendizagem dentro do SUS, para normatizar os campos de integração ensino-serviço nos municípios e regiões para campo de trabalho e estágio dos estudantes. A parceria com o Ministério da Educação foi estabelecida para pensar e articular iniciativas de formação e de mudanças nos currículos dos cursos e nas práticas profissionais, visando uma formação com perfil que atenda às necessidades de saúde pública ${ }^{14}$. A construção desta política reafirma os princípios democráticos do SUS, aponta o fortalecimento da gestão participativa e da responsabilidade compartilhada, com dispositivos que ampliem os espaços para o exercício do diálogo e a busca de respostas coletivas para problemas que impedem a atenção integral.

A EPS parte do pressuposto da aprendizagem significativa - a aprendizagem que produz sentido para o sujeito, faz a interlocução com os problemas enfrentados na realidade e leva em consideração os conhecimentos e experiências que os sujeitos possuem ${ }^{15}$. Para que a aprendizagem se torne significativa, a construção do conhecimento passa pela problematização, para refletir sobre determinadas situações, ideias, compreendendo os processos e propondo respostas e soluções. Ao refletir sobre a situação concreta de trabalho, as propostas de soluções passam a ser mais reais, viáveis e, sobretudo, descentralizadas e compartilhadas.

No contexto do SUS, a problematização foi adotada para construção de relações baseadas em uma prática pedagógica transformadora, em que os sujeitos são motivados a experimentar uma maneira diferente de ver o mundo, numa postura crítica e ativa para solução de problemas que são coletivos. Esse processo, em oposição a uma educação de dominação, leva a romper com a postura de transmissão de informações e passividade, revira antigas certezas e provoca a participação ativa dos sujeitos envolvidos.

Entretanto, a adoção dos preceitos neoliberais pelo governo federal, que se intensifica a partir dos anos 1990, analisa profundamente Machado ${ }^{16}$, produziu efeitos prejudiciais na implantação do SUS e resultou não apenas na precarização do trabalho, sobretudo o modo de trabalhar sofreu alterações significativas, foi influenciado por ambientes de trabalho cada vez mais complexos, competitivos e individualizados.

A reflexão mostra que a implementação da política de EPS em 2007, ainda está distante da realidade de alguns serviços e é um desafio a ser enfrentado ${ }^{5}$ pelo Serviço Social e demais profissões da saúde.

0 trabalho é a atividade que mediatiza a satisfação das necessidades humanas, seja ela material ou intelectual, que o homem dá respostas às suas necessidades. Portanto, é mediante o processo de trabalho que o homem se socializa e projeta a concepção de sociedade desejada, a que exclui, explora, individualiza, ou aquela que propicia o desenvolvimento de novos valores e concepções, o que supõe a erradicação dos processos de exploração, opressão e alienação.

0 produto do trabalho em saúde deve, antes de tudo, responder a algumas necessidades humanas; em outras palavras, deve ser útil às necessidades de saúde como um direito da população.

É quando a EPS assume papel fundamental, que possibilita aliar formação com trabalho e questiona, problematiza, revira conceitos e valores, e pode provocar novas posturas para o enfrentamento coletivo dos desafios colocados pela ofensiva neoliberal. 0 desafio é pensar uma nova pedagogia na saúde que possa implicar a construção de sujeitos comprometidos sócio historicamente com a construção da vida e da saúde, e sua defesa social e coletiva. Desse modo, problematizar as questões da saúde é tornar a reflexão e análise uma prática associada ao trabalho, é agir ativamente para acolher as incertezas e o estranhamento. Isso deve permitir valorizar as capacidades, desenvolver as potencialidades existentes em cada realidade para a aprendizagem significativa na saúde.

A análise desta conjuntura demonstra que as limitações não se restringem ao setor saúde, nem aos municípios e suas regiões. 0 Estado brasileiro ainda não está voltado à 
edificação das reformas sociais necessárias a superação da negatividade dos determinantes sociais na vida da população. Portanto, a formação dos trabalhadores de saúde, como uma centralidade de análise para a efetivação do direito à saúde, indica pensar a articulação dos espaços na sociedade e a importância deste debate dentro da universidade e sua participação neste movimento da saúde.

0 trabalho em saúde é um trabalho coletivo, e a EPS valoriza esta dimensão. $\mathrm{Na}$ saúde toda atividade é realizada por um trabalhador de dimensão coletiva, o trabalho de um se organiza com o do outro, portanto, o modo como ele se organiza é importante para entender o funcionamento da sociedade atual e da própria saúde que está sendo desenvolvida ${ }^{17}$.

Assim, ao reconhecer que a capacidade criadora do homem se manifesta no trabalho, condição especificamente humana de transformar a natureza em coisas úteis, segundo os seus interesses, é por meio dessa relação com a natureza que o homem se constitui e se transforma. Nas palavras de Marx ${ }^{18}$ - "põe em movimento as forças naturais de seu corpo - pernas e braços, cabeça e mãos - a fim de apropriar-se dos recursos da natureza, imprimindo-lhes vida útil à vida humana".

\section{CONCLUSÃO}

0 desenvolvimento da pesquisa trouxe contribuições significativas e avanços na área de conhecimento das ciências sociais, especialmente em relação ao campo de formação de recursos humanos para a saúde, buscando potencializar a integração ensinoserviço.

A opção de trazer a Política de Educação Permanente em Saúde para o cenário da universidade, reconhece esta como uma estratégia político-pedagógica construída para consolidar o modelo de atenção previsto no SUS. A universidade tem um papel fundamental de subsidiar esse processo e ampliar as opções de atividades e experiências na formação dos alunos. Assim, torna-se prioridade a articulação intersetorial na formulação de ações e que aproximem as diferentes realidades sociais dos municípios e regiões ao processo pedagógico da formação para a saúde.

A participação no Grupo QUAVISSS e a construção dos espaços de aprendizagem para o exercício coletivo do diálogo favoreceram a socialização do conhecimento e de experiências desenvolvidas no âmbito local-regional, estabelecendo uma relação com as questões de relevância social, política, econômica e cultural. Inclusive, permitindo a aprendizagem do aluno pela vivência e experiência.

A importância acadêmica e social do estudo revela que no cenário contemporâneo as profissões precisam dar respostas qualificadas aos problemas enfrentados, exigindo coragem de pensar a saúde numa perspectiva transformadora e em constante movimento de desconstrução e reconstrução de ideias, sentidos e conceitos. Assim, a pesquisa científica é fundamental para tornar visíveis as trajetórias de lutas, resistências e respostas, como fonte de informações e experiências.

Os resultados demonstram que as possibilidades de novos aprendizados vão ao encontro das necessidades sentidas e vividas pelos sujeitos. Evidenciam o significado mais abrangente da formação profissional associada ao trabalho, que resulta em benefícios e na própria defesa do sistema público de saúde. E mostram, ainda, que a EPS é de difícil exercício, já que busca a ruptura com a prática verticalizada, centralizadora e centrada na doença, e ao adotar a metodologia ativa para problematizar a formação e o trabalho em saúde, estimula nos sujeitos o compromisso ético e político com a saúde pública.

Considera-se que a EPS é uma estratégia que potencializa a integração ensino-serviço e a busca de respostas aos problemas, provocando interesses na participação de grupos e atividades, em temáticas de novas pesquisas científicas, de participações em eventos científicos, projetos e atividades. E, sobretudo, o exercício da EPS possibilita problematizar interesses, sentimentos, e integrar os sujeitos para o 
desafio coletivo de aprender a (re) construir saúde.

\section{REFERENCIAS}

1. Minayo MCS. O desafio do conhecimento: pesquisa qualitativa em saúde. 11ed. São Paulo: Hucitec; 2010.

2. Ministério da Saúde (Br). Portaria no 1996/GM/MS, de 20 de agosto de 2007. Dispõe sobre as diretrizes para a implementação da Política Nacional de Educação Permanente em Saúde e dá outras providências. Brasília: Ministério da Saúde; 2007.

3. Paulo Netto J. Crise do capital e consequências societárias. Serv Soc Soc. [Internet] 2012 [citado em 15 de out 2014]; 111:413-29. Disponível em: http://www.scielo.br/pdf/sssoc/n111/a02.pdf

4. Bravo MIS, Matos MC. Projeto ético-político do Serviço Social e sua relação com a reforma sanitária: elementos para o debate. In: Mota $\mathrm{AE}$, Gomes L, Bravo MIS, Teixeira M, Marsiglia RMG, Uchôa R. (Org.). Serviço Social e saúde: formação e trabalho profissional. São Paulo: Cortez; 2009. p.197-217.

5. Conselho Federal de Serviço Social. Parâmetros para atuação de assistentes sociais na saúde. Brasília: CFESS; 2010. (Trabalho e Projeto Profissional nas Políticas Sociais).

6. Guerra Y. A dimensão investigativa no exercício profissional. In: Serviço Social: direitos sociais e competências profissionais. Brasília: CFESS/APEPSS; 2009. p.701-718.

7. Kosik K. Dialética do concreto. 6ed. Neves C, Toríbio A, tradutores. Rio de Janeiro: Paz e Terra; 2010.

8. Martinelli ML. (Org). Pesquisa qualitativa: um instigante desafio. 2ed. São Paulo: Veras; 2012.

9. Sareta FO, Eto F. A integração do ensinoserviço a partir das experiências do Grupo QUAVISSS. In: Sarreta FO, ETO F, Pereira LT. (Org.). Formação e trabalho na saúde: reafirmando o SUS constitucional. Franca/SP: Editora UNESP; 2013. v. 1, p.115-22.

10. Minayo MCS. Pesquisa social: teoria, método e criatividade. 18ed. Petrópolis: Vozes; 2001.

11. Ressel LB, Beck CLC, Gualda DMR, Hoffmann IC, Silva RM, Sehnem GD. O uso do grupo focal em pesquisa qualitativa. Texto e Contexto Enferm. [Internet] 2008 [citado em 15 out 2014]; 17(4):779-86. Disponível em: http://www.scielo.br/pdf/tce/v17n4/21.pdf.

12. Backes DS, Colomé JS, Erdmann RH, Lunardi

VL. Grupo focal como técnica de coleta e análise de dados em pesquisas qualitativas. 0 Mundo da Saúde. 2011; 35(4):438-42.
13. Ministério da Saúde (Br). Lei no. 10.424 de 15 de abril de 2002. Acrescenta capítulo e artigo à Lei no. 8.080, de 19 de setembro de 1990, que dispõe sobre as condições para a promoção, proteção e recuperação da saúde, a organização e o funcionamento de serviços correspondentes e dá outras providências, regulamentando a assistência domiciliar no Sistema Único de Saúde [Internet]. D.O.U. Brasília, 16 abr 2002 [citado em 15 de out 2014]. Disponível em: http://www.planalto.gov.br/ccivil_03/leis/2002 /l10424.htm.

14. Sarreta FO. 0 trabalho em saúde: desafios da educação permanente em saúde. In: VIII Seminário de Saúde do Trabalhador de Franca [Internet]; 2012; Franca. Franca: UNESP; 2012 [citado em 15 out 2014]. Disponível em: http://www.proceedings.scielo.br/scielo.php?scr $\mathrm{ipt}=$ sci_arttext $\&$ pid=MSC0000000112012000100 049\&lng=en\&nrm=abn.

15. Sarreta FO. Educação permanente em saúde para os trabalhadores do SUS. São Paulo: Cultura Acadêmica, UNESP; 2010.

16. Machado MH. Trabalhadores de saúde e sua trajetória na reforma sanitária. Cad RH Saúde. 2006; 3(1):32-43.

17. Merhy EE. O trabalho em saúde: olhando e experenciando o SUS no cotidiano. 4ed. São Paulo: Hucitec; 2007.

18. Marx K. O capital: crítica da economia política. Enderle, Rubens, tradutor. 23ed. São Paulo: Boitempo; 2013. p.42. Livro I: 0 processo de produção do capital.

\section{CONTRIBUIÇÕES}

Fernanda de Oliveira Sarreta é coordenadora do projeto de pesquisa e responsável pela concepção do estudo e redação final do artigo. Fumie Eto participou do desenvolvimento de todas as etapas do projeto de pesquisa e redação final do artigo. Daiane Cristina dos Santos Brentini, Danielle de Oliveira Nogueira, Gabriela Cristina Braga Bisco participaram na coleta dos dados e redação do artigo.

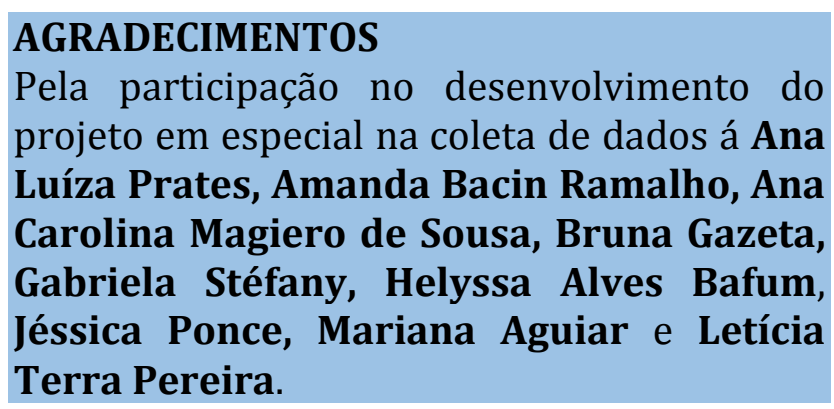

REFACS (online) 2016; 4(1):17-25. 